\title{
Equations of state of unreacted explosives: PETN, RDX, HMX, TATB
}

\author{
B.A. Nadykto \\ RFNC-VNIIEF, Sarov, Nizhniy Novgorod Region 607190, Russia
}

\begin{abstract}
For most of explosive conversion kinetics simulations associated with the analysis of HE initiation, safety of HE handling, accidents, etc., one needs to know the equation of state of yet unreacted ("cold") HE. Acquisition of experimental data for such materials poses a real challenge, such data are rather scarce, and their accuracy does not allow plotting continuous curves at all times. In this case, computational, theoretical and semi-empirical approaches that involve a limited number of available experimental points can provide a more detailed description of HE behavior.
\end{abstract}

\section{Introduction}

In this paper, the equation of state of "cold" HE was calculated using the approach of Refs. [1-3], which is usefully employed to calculate equations of state of different inert materials in a wide range of pressures. Just as for many inert materials, as pressure increases with HE compression, compressibility of the material undergoes a strong variation, which is described by changes in the EOS parameters.

\section{Equation of state of PETN}

Experimental data on the shock compression of single-crystal unreacted PETN are presented in [4] for pressures up to $14 \mathrm{GPa}$. Experimental curves of D-u, P- $\rho$ and P-u [1] display a change in their slope around $\mathrm{u}=0.61 \mathrm{~km} / \mathrm{s}, \mathrm{D}=3.8 \mathrm{~km} / \mathrm{s}, \mathrm{P}=4.15 \mathrm{GPa}, \rho=2.11 \mathrm{~g} / \mathrm{cm}^{3}$. This change in the slope can be explained by a compression-induced change in the electron structure of PETN. Therefore, the equation of state for PETN was chosen in the form of two regions with different parameters for each phase:

$$
\text { I } \rho_{\mathrm{o}}=1.86 \mathrm{~g} / \mathrm{cm}^{3}, \mathrm{~B}_{\mathrm{o}}=22.2 \mathrm{GPa} ; \quad \text { II } \rho_{\mathrm{o}}=1.96 \mathrm{~g} / \mathrm{cm}^{3} ; \mathrm{B}_{\mathrm{o}}=37.6 \mathrm{GPa} \text {. }
$$

For the pressure $\mathrm{P}<0.3 \mathrm{GPa}$, the EOS parameters are $\rho_{\mathrm{o}}=1.86 \mathrm{~g} / \mathrm{cm}^{3} ; \mathrm{B}_{\mathrm{o}}=11.2 \mathrm{GPa}$. For normal conditions, at $\rho_{\mathrm{oo}}=1.774 \mathrm{~g} / \mathrm{cm}^{3}$, the value of the bulk compression modulus is $\mathrm{B}=9.69 \mathrm{GPa}$. The paper provides a comparison of calculated values with static measurement data for the dependence of pressure on the degree of compression on the normal isotherm in PETN [5].

Figures 1-3 show a comparison of calculated values with experimental data. Despite the comparatively wide scatter of experimental data, all the D-u, P- $\rho$ and P-u curves are on the average reasonably well described by the proposed equation of state. Perhaps the closest agreement between calculated and experimental values is observed for the P-u curve.

Reference [5] presents static measurement data for the dependence of pressure on the degree of compression on the normal isotherm in PETN. The experimental points were obtained by the diamond anvil method using synchrotron radiation for X-ray diffraction measurements. Figure 4 shows a comparison of the normal isotherm with the Hugoniot. The equation of state of PETN chosen for

This is an Open Access article distributed under the terms of the Creative Commons Attribution-Noncommercial License 3.0, which permits unrestricted use, distribution, and reproduction in any noncommercial medium, provided the original work is properly cited. 


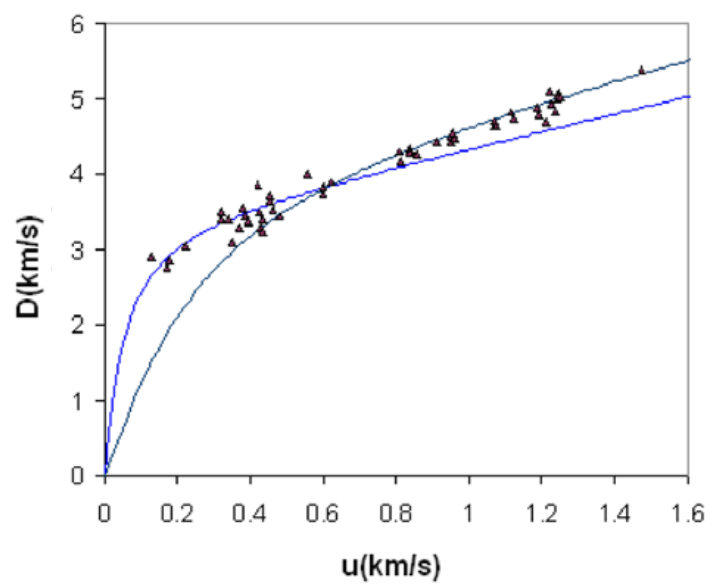

Fig. 1. The D-u curve for single-crystal PETN. The experimental data are from Ref. [4]. The curves represent our calculations for two different phases of PETN.

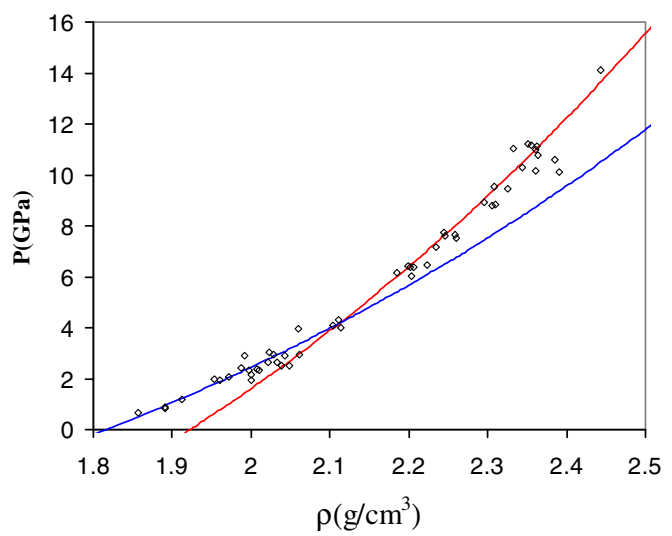

Fig. 2. The $\mathrm{P}(\rho)$ curve on the Hugoniot for single-crystal PETN. The experimental data are from Ref. [4]. The curves represent our calculations for two different phases of PETN.

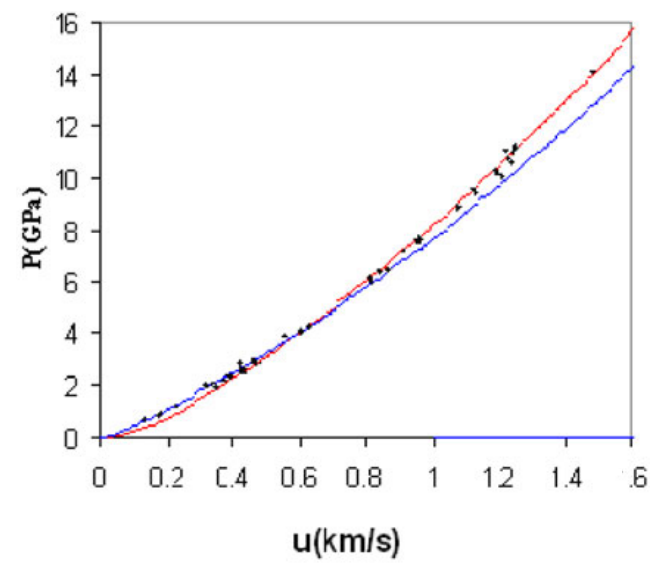

Fig. 3. The $\mathrm{P}(\mathrm{u})$ curve on the Hugoniot for single-crystal PETN. The experimental data are from Ref. [4]. The curves represent our calculations for two different phases of PETN. 


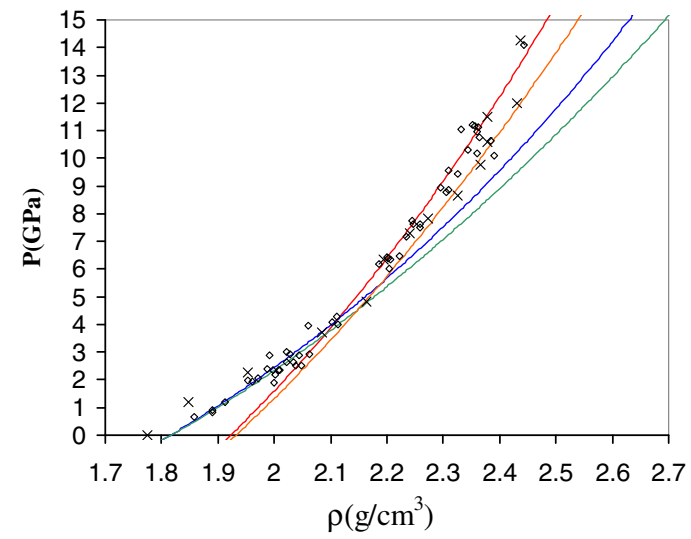

Fig. 4. Comparison of the $\mathrm{P}(\rho)$ curves on the Hugoniot and normal isotherm for single-crystal PETN. Experimental data: triangles represent data from Ref. [4] on the Hugoniot; and solid circles show data from Ref. [5] on the normal isotherm. The curves represent our calculations for two different phases of PETN. The upper curve is for the Hugoniot, and the lower one is for the normal isotherm.

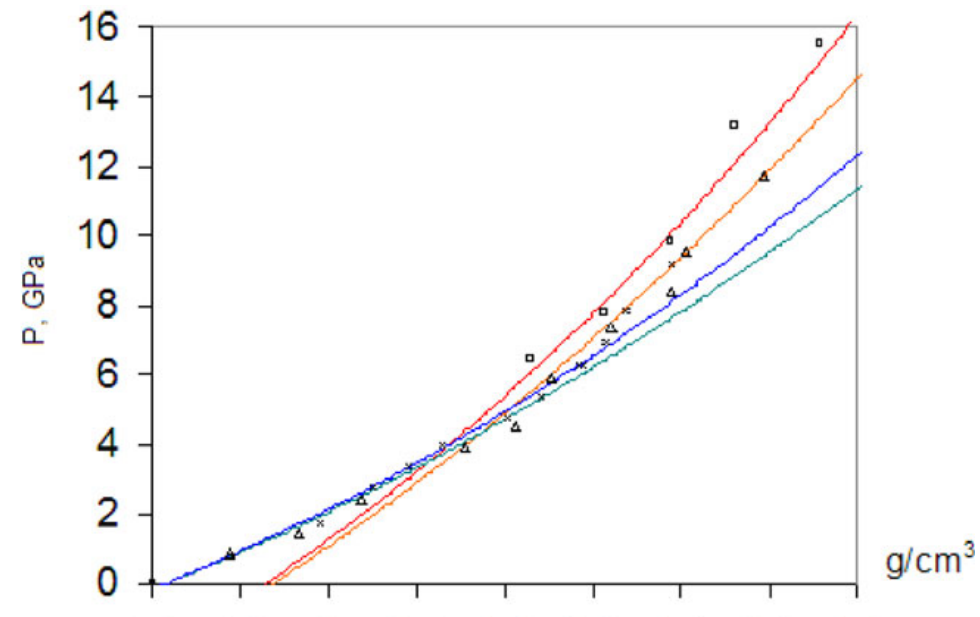

\section{$\begin{array}{llllllllll}1.8 & 1.9 & 2 & 2.1 & 2.2 & 2.3 & 2.4 & 2.5 & 2.6\end{array}$}

Fig. 5. The $\mathrm{P}(\rho)$ curve for crystalline RDX. Experimental data: squares are for measurements on the Hugoniot [6], triangles are for diamond-anvil static measurements [5], and crosses are for Bridgman anvil static compression measurements [7]. The curves represent our calculations for two different phases of RDX.

the description of shock-wave experiments [4] provides a reasonable description of static measurement results [5] on the normal isotherm of PETN. The calculated input from thermal pressure on the Hugoniot at a pressure of 5-14 GPa does not exceed $11 \%$. This difference is hard to resolve based on experimental data because of measurement errors, but almost all points lie in the range between the calculated curves for the Hugoniot and normal isotherm. The data of static experiments required no revision of the equation of state.

\section{Equation of state of RDX}

Experimental data on the shock compression of crystalline unreacted RDX are presented in [6] for pressures up to $15.5 \mathrm{GPa}$. The experimental data of Refs. [6,8] for RDX show that the $\mathrm{P}(\rho)$ curves change their slope around $\mathrm{P}=4.9 \mathrm{GPa}, \rho=2.2 \mathrm{~g} / \mathrm{cm}^{3}$. This change in the slope can be explained by 


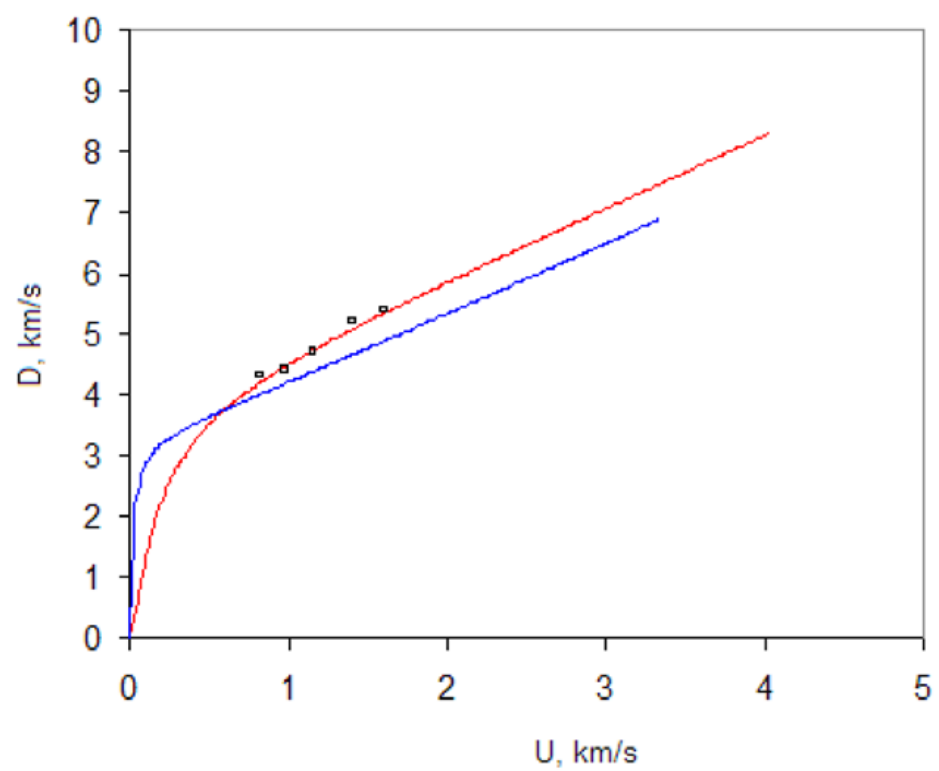

Fig. 6. The D-u curve for single-crystal RDX. The experimental data (squares) are from Ref. [6]. The curves represent our calculations for two different phases of RDX.

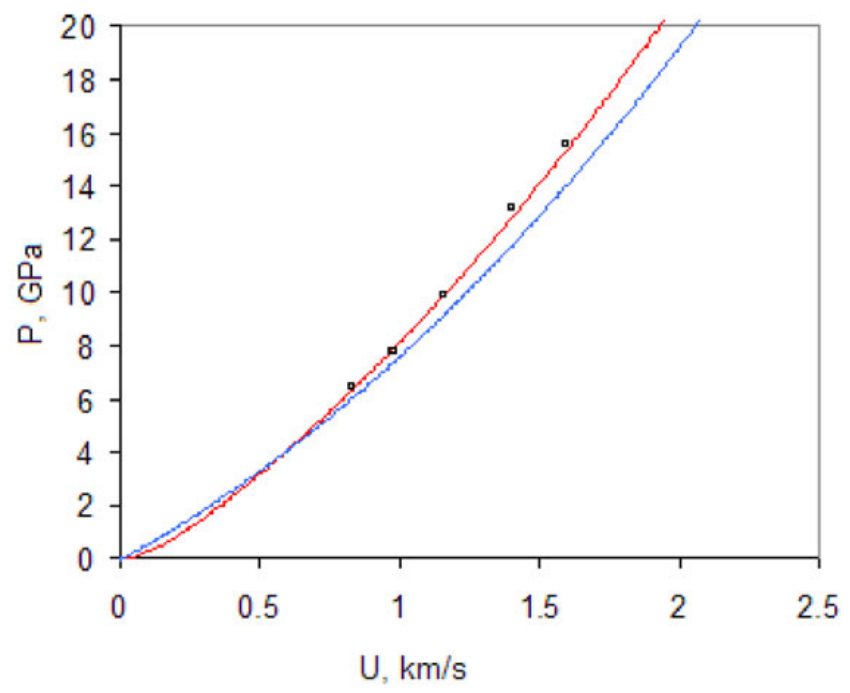

Fig. 7. The $\mathrm{P}(\mathrm{u})$ curve on the Hugoniot for crystalline RDX. The squares represent experimental data measured on the Hugoniot from Ref. [6]. The curves represent our calculations for two different phases of RDX.

a compression-induced change in the electron structure of PETN. Therefore, the equation of state for RDX was chosen in the form of two regions with different parameters for each phase:

$$
\text { I } \rho_{\mathrm{o}}=1.866 \mathrm{~g} / \mathrm{cm}^{3}, \mathrm{~B}_{\mathrm{o}}=19.6 \mathrm{GPa} ; \quad \text { II } \quad \rho_{\mathrm{o}}=1.97 \mathrm{~g} / \mathrm{cm}^{3} ; \mathrm{B}_{\mathrm{o}}=33.0 \mathrm{GPa} \text {. }
$$

Figures 5-7 show a comparison of calculated values with experimental data. Despite the comparatively wide scatter of experimental data, all the D-u, P- $\rho$ and P-u curves are on the average reasonably well described by the proposed equation of state. 


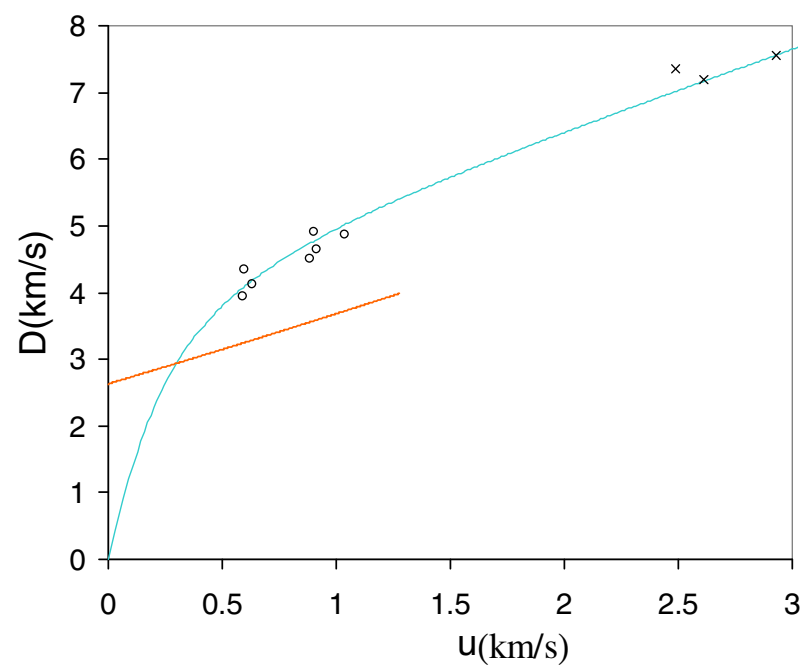

Fig. 8. The D-u curve for HMX. Experimental data: rhombs are for single-crystal HMX from Ref. [4], and crosses are for compacted samples from Ref. [4]. The curves represent our calculations for HMX.

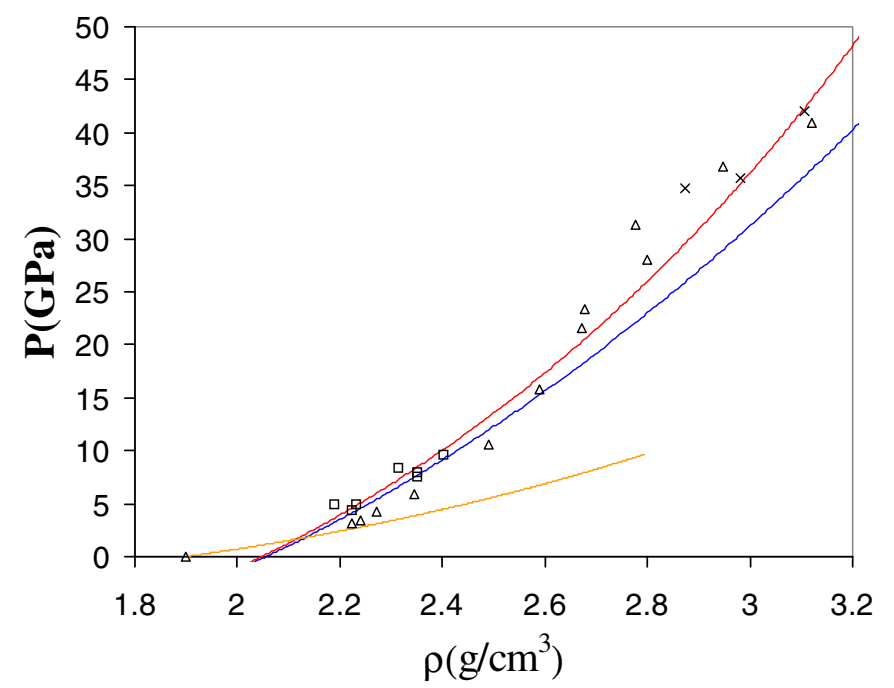

Fig. 9. The $\mathrm{P}(\rho)$ curve for single-crystal HMX. Experimental data: rhombs are for compacted samples and crosses are for single-crystal HMX from Ref. [4] (measured on the Hugoniot); triangles are for diamond anvil static compression data from Ref. [5]. The curves represent our calculations for HMX. The upper curve is for the Hugoniot, and the lower one is for the normal isotherm.

\section{Equation of state of $\mathrm{HMX}$}

For HMX, Ref. [4] provides three experimental points on the Hugoniot for single-crystal samples $\left(\rho_{\mathrm{oo}}=1.90 \mathrm{~g} / \mathrm{cm}^{3}\right)$ and seven points for compacted samples $\left(\rho_{\mathrm{oo}}=1.891 \mathrm{~g} / \mathrm{cm}^{3}\right)$. Experimental points in Ref. [4] for the single-crystal and compacted samples lie on the same computational curve with the parameters $\rho_{\mathrm{o}}=2.024 \mathrm{~g} / \mathrm{cm}^{3} ; \mathrm{B}_{\mathrm{o}}=44.2 \mathrm{GPa}$. The EOS parameters for low pressures are $\rho_{\mathrm{o}}=$ $1.97 \mathrm{~g} / \mathrm{cm}^{3} ; \mathrm{B}_{\mathrm{o}}=19.6 \mathrm{GPa}$.

Figures 8-10 show a comparison of calculated values with experimental data of Ref. [1].

In addition to the data of shock experiments of Ref. [4], for $\mathrm{P}(\rho)$, there are static measurement data on the normal isotherm of HMX in diamond anvils [5,7]. When choosing the equation of state, we preserve the parameters obtained from the description of shock experiments. In the range of low 


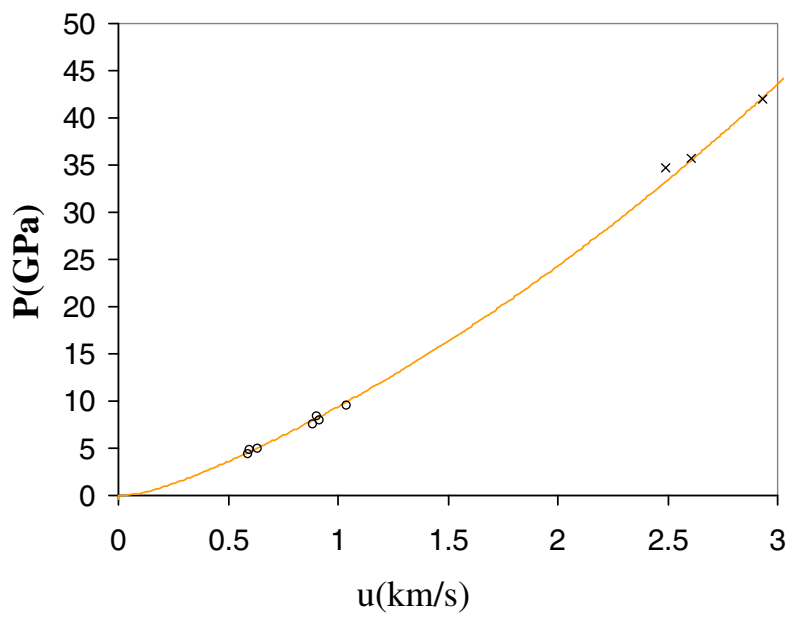

Fig. 10. The $\mathrm{P}(\mathrm{u})$ curve on the Hugoniot for HMX. Experimental data: rhombs are for single-crystal HMX from Ref. [4], and crosses are for compacted samples from Ref. [4]. The curves represent our calculations for HMX.

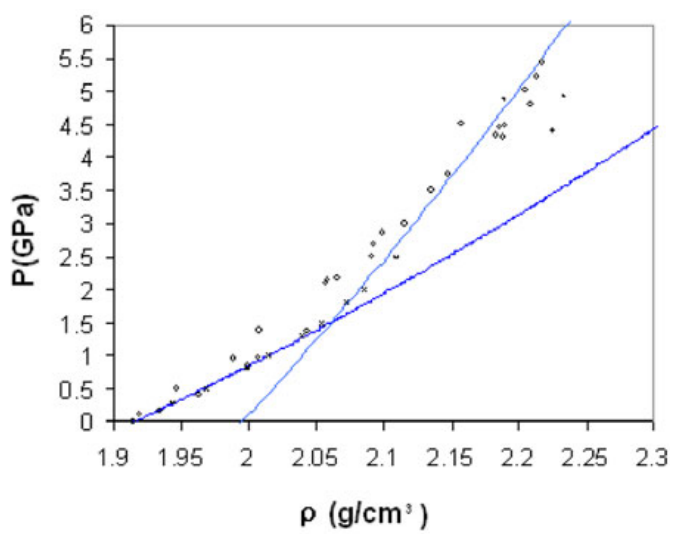

Fig. 11. The $\mathrm{P}(\rho)$ curve on the normal isotherm for crystalline HMX. Data of static experiments: Crosses are from Ref. [8], and rhombs are from Ref. [9]. The curves represent our calculations for two electron phases of HMX.

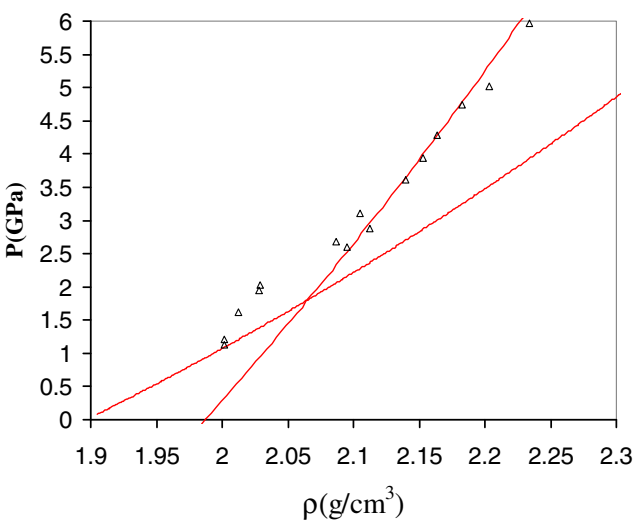

Fig. 12. The $\mathrm{P}(\rho)$ curve on the isotherm of $100^{\circ} \mathrm{C}$ for crystalline HMX. Data of static experiments: triangles are from Ref. [9]. The curves represent our calculations for two electron phases of HMX. 
New Models and Hydrocodes for Shock Wave Processes in Condensed Matter

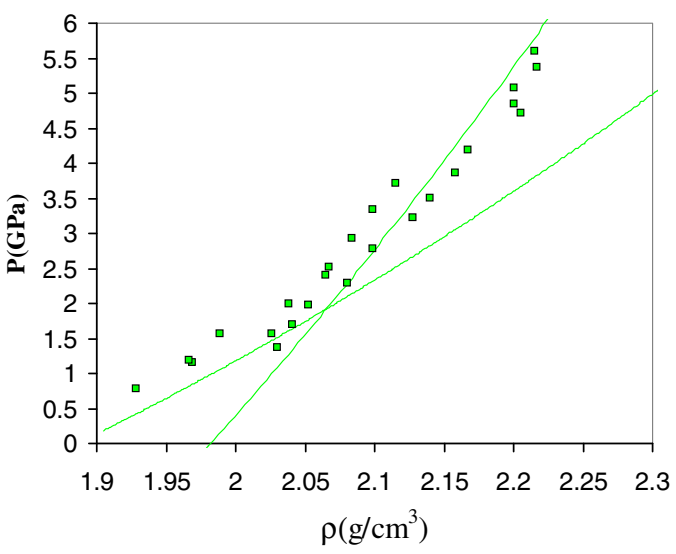

Fig. 13. The $\mathrm{P}(\rho)$ curve on the isotherm of $140^{\circ} \mathrm{C}$ for crystalline HMX. Data of static experiments: triangles are from Ref. [9]. The curves represent our calculations for two electron phases of HMX.

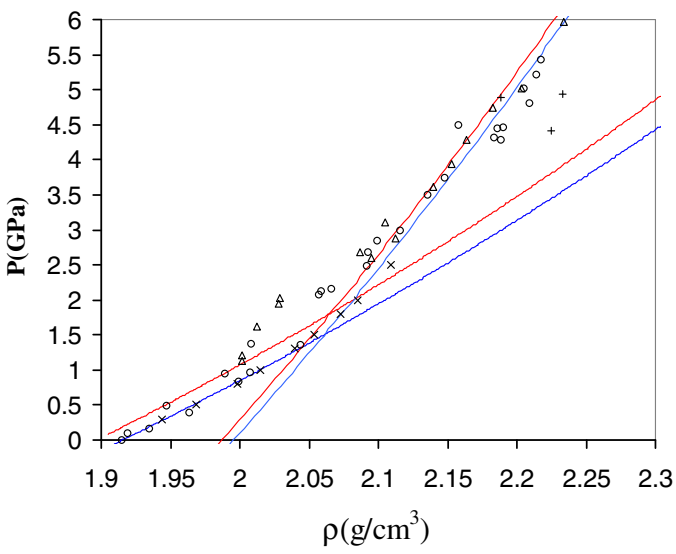

Fig. 14. The $\mathrm{P}(\rho)$ curve on the normal isotherm and isotherm of $100^{\circ} \mathrm{C}$ for crystalline HMX. The calculations provide a more reasonable estimate of pressure difference on these isotherms.

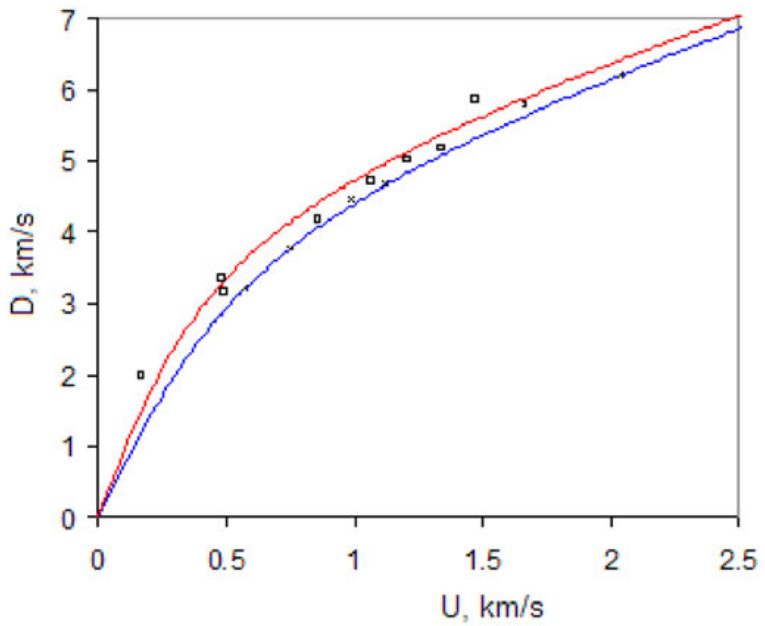

Fig. 15. The D-u curve for TATB. Experimental data: squares are for $\rho_{\mathrm{oo}}=1.876 \mathrm{~g} / \mathrm{cm}^{3}$ from Ref. [10], and crosses are for $\rho_{\mathrm{oo}}=1.806 \mathrm{~g} / \mathrm{cm}^{3}$ from Ref. [11]. The curves represent our calculations. The upper curve is for $\rho_{\mathrm{oo}}=1.876 \mathrm{~g} / \mathrm{cm}^{3}$, and the lower curve is for $\rho_{\mathrm{oo}}=1.806 \mathrm{~g} / \mathrm{cm}^{3}$. 


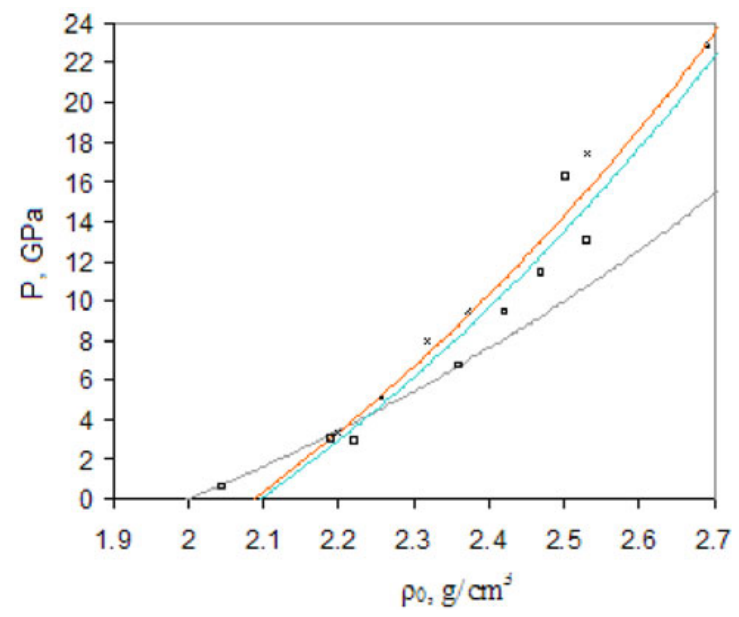

Fig. 16. The $\mathrm{P}(\rho)$ curve for TATB. Experimental data: squares are for $\rho_{\mathrm{oo}}=1.876 \mathrm{~g} / \mathrm{cm}^{3}$ from Ref. [10], and crosses are for $\rho_{\mathrm{oo}}=1.806 \mathrm{~g} / \mathrm{cm}^{3}$ from Ref. [11]. The curves represent our calculations. The upper curve is for $\rho_{\mathrm{oo}}=1.806 \mathrm{~g} / \mathrm{cm}^{3}$, and the lower curve is for $\rho_{\mathrm{oo}}=1.876 \mathrm{~g} / \mathrm{cm}^{3}$.

pressures, one should use other EOS parameters. In this pressure range, one can use the data of Ref. [8] on the normal isotherm, and those of Ref. [9] on the normal isotherm and isotherms of $100^{\circ} \mathrm{C}$ and $140{ }^{\circ} \mathrm{C}$.

In addition to the data of shock experiments from Ref. [4], Fig. 9 shows data of diamond anvil static measurements on the normal isotherm of HMX for the $\mathrm{P}(\rho)$ curve [5,7]. The normal isotherm measured at pressures below $15 \mathrm{GPa}$ is close to the calculated normal isotherm. At pressures above $20 \mathrm{GPa}$, experimental points of the measured normal isotherm are 13 to 28 percent higher than the calculated normal isotherm. One should note the wide scatter of static measurement data and the fact that most of them lie above the Hugoniot at pressures above $20 \mathrm{GPa}$. This is probably attributed to the failure to provide hydrostatic (all-around) compression. Ref. [5] also points to the fact that there were no chemical reactions under hydrostatic compression in the experiment and that they were observed under non-hydrostatic compression. When choosing the equation of state, we preserve the parameters obtained from the description of shock experiments.

The aforementioned EOS parameters fail to describe the behavior of HMX at pressures below 4 $\mathrm{GPa}$, and in this range, as in the case of other types of explosive, other EOS parameters corresponding to a different electron phase of HMX should be used. In this pressure range one can use experimental data presented in Refs. [8,9]. Reference [8] present data for the normal isotherm, and Ref. [9] for the normal isotherm and isotherms of $100^{\circ} \mathrm{C}$ and $140^{\circ} \mathrm{C}$. The EOS parameters for low pressures are $\rho_{\mathrm{o}}=1.97 \mathrm{~g} / \mathrm{cm}^{3} ; \mathrm{B}_{\mathrm{o}}=19.6 \mathrm{GPa}$. Figures $11-15$ show a comparison with experimental data from Refs. [8,9]. For the normal isotherm, calculations reproduce experimental data [8,9] (Fig. 11) quite reasonably. A close agreement with data [9] shown in Fig. 12 for the isotherm of $100^{\circ} \mathrm{C}$ is obtained for $\mathrm{P}>2.5 \mathrm{GPa}$. The accuracy of data for the isotherm of $140^{\circ} \mathrm{C}$ is noticeably lower, but experimental data display a clear kink of the $\mathrm{P}(\rho)$ curve at approximately $2 \mathrm{GPa}$ (see Fig. 13).

Figure 14 shows the $\mathrm{P}(\rho)$ curve on the normal isotherm and the isotherm of $100{ }^{\circ} \mathrm{C}$ for crystalline HMX. Calculations provide a more reasonable estimate of pressure difference on these isotherms. It is rather difficult to determine this difference directly from experimental data. This particularly clearly follows from Fig. 15, which summarizes all experimental data and calculated results.

\section{Equation of state of TATB}

Experimental data for TATB having a density of $1.876 \mathrm{~g} / \mathrm{cm}^{3}$ for pressures up to $16 \mathrm{GPa}$ are presented in Ref. [10]. For TATB having a density of $1.876 \mathrm{~g} / \mathrm{cm}^{3}$, experimental data are presented in Ref. [11]. The equation of state for cold TATB was chosen in the form of two regions with different 


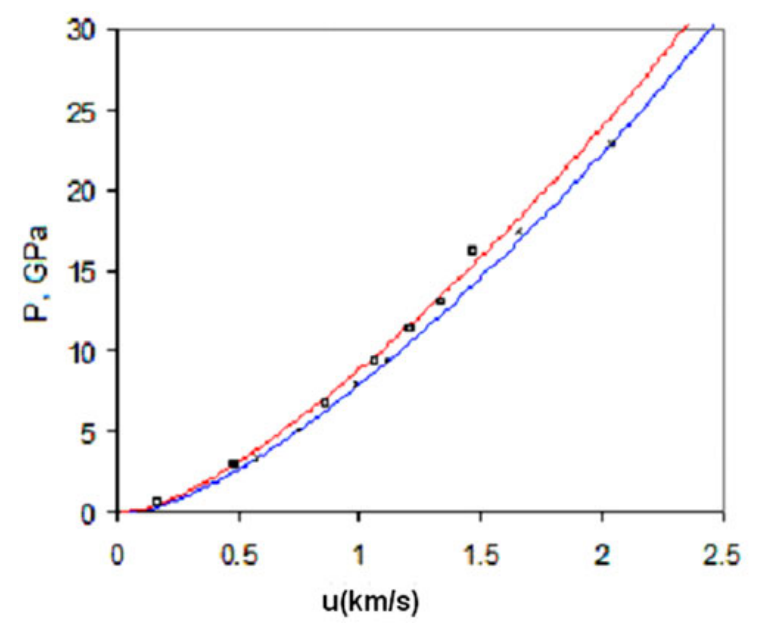

Fig. 17. The $\mathrm{P}(\mathrm{u})$ curve for TATB. Experimental data: squares are for $\rho_{\mathrm{oo}}=1.876 \mathrm{~g} / \mathrm{cm}^{3}$ from Ref. [10], and crosses are for $\rho_{\mathrm{oo}}=1.806 \mathrm{~g} / \mathrm{cm}^{3}$ from Ref. [11]. The curves represent our calculations. The upper curve is for $\rho_{\mathrm{oo}}=1.876 \mathrm{~g} / \mathrm{cm}^{3}$, and the lower curve is for $\rho_{\mathrm{oo}}=1.806 \mathrm{~g} / \mathrm{cm}^{3}$.

parameters:

$$
\begin{aligned}
\text { I } \rho_{\mathrm{o}} & =1.966 \mathrm{~g} / \mathrm{cm}^{3} ; \mathrm{B}_{\mathrm{o}}=16 \mathrm{GPa} . \quad \text { II } \rho_{\mathrm{o}}=2.05 \mathrm{~g} / \mathrm{cm}^{3} ; \mathrm{B}_{\mathrm{o}}=37 \mathrm{GPa} . \\
\text { At } \mathrm{T} & =293 \mathrm{~K}, \rho_{\mathrm{o}}=1.91 \mathrm{~g} / \mathrm{cm}^{3}, \mathrm{E}_{0}=0.2057 \mathrm{~kJ} / \mathrm{g}, \text { and } \mathrm{C}_{V}=1.01 \mathrm{~J} / \mathrm{g} \mathrm{K} .
\end{aligned}
$$

Figures 15-17 show a comparison of calculated values with experimental data. All the D-u, P- $\rho$ and $\mathrm{P}-\mathrm{u}$ curves are well described by the proposed equation of state.

\section{Summary}

Equations of state for cold (unreacted) PETN, RDX, HMX and TATB explosives have been calculated.

Experimental data display a discontinuity in the compressibility of cold explosives, which can be described in calculations by a change in the parameters of the equation of state, while preserving its analytical form.

\section{References}

1. Nadykto B.A.//UFN. 1993. V. 163, No. 9. P. 37.

2. Nadykto B.A.//VANT. Ser.: Theoretical and Applied Physics. 1996. Issue 3. P. 58.

3. Nadykto B.A. Advances in Material Science. Edited by D. Kusnezov, O.N. Shubin. P. V-9.

4. LASL Shock Hugoniot Data. Edit. S.P. Marsh. University of California Press. Berkeley. Los Angeles. London. 1980. P. 621-622.

5. C.-S. Yoo, H. Cynn, W.M. Howard, N. Holmes. // $11^{\text {th }}$ International Detonation Symposium, Snowmass, Co, 30 August to 4 September, 1998. P. 951-957.

6. V.S. Ilyukhin, P.F. Pokhil, O.K. Rozanov, N.S. Shvedova. // Transactions of the Soviet Academy of Sciences. 1960. V. 131, No. 4. Pp. 793-796.

7. Olinger B., Roof R.B., Cady H. Proceedings to Symposium H. D. P. (Commissariat a l'Energie Atomique, 1978). Pp. 3-8.

8. V.V. Adushkin, L.V. Lariononov, L.D. Livshits, G.I. Syrenkov, K.N. Shamshchev. Transactions of the Soviet Academy of Sciences. 1991. V. 317, No.1. Pp. 103-104.

9. J.C. Gump, S.M. Peiris. J. Appl. Phys. 97, 053513 (2005).

10. LASL Shock Hugoniot Data. Edit. S.P. Marsh. University of California Press. Berkeley. Los Angeles. London. 1980. P. 626.

11. B.M. Dobratz. The Insensitive High Explosive Triaminotrinitrobenzene (TATB): Development and Characterization - 1888 to 1994. LA-13014-H. P. 64. 